\title{
TORCER: \\ A METAFÍSICA DO HOMEM COMUM
}

\begin{abstract}
Luiz Henrique de Toledo
Doutor em Antropologia pela Faculdade de Filosofia, Letras e Ciências Humanas da Universidade de São Paulo e professor de Antropologia na Universidade Federal de São Carlos.
\end{abstract}

\section{Resumo}

Procuro, neste artigo, articular as formas de torcer que historicamente engendraram a sociabilidade em torno do futebol. Para tanto, discuto as transformações na sensibilidade torcedora que, acossada pelas experiências tecnológicas, mercadológicas e subjetivas do individualismo, tendeu a esvaziar algumas das experiências públicas e coletivizadoras responsáveis pela alta projeção do futebol como mediador das relações lúdicas cotidianas nos centros urbanos brasileiros.

\section{Pallavras-chave}

futebol $\bullet$ sociabilidade $\bullet$ torcedor $\bullet$ antropologia das práticas esportivas $\bullet$ torcidas.

Correspondência

Universidade Federal de São Carlos (UFSCar)

Rodovia Washington Luis, km 235, SP-310

13565-905 - São Carlos - São Paulo

E-mail: kike@usp.br 


\title{
SUPPORT: METAFISICAL OF ORDINARY PEOPLE:
}

\begin{abstract}
Luiz Henrique de Toledo
Ph.D. in Antropology, Faculdade de Filosofia, Letras e Ciências Humanas of the Universidade de São Paulo and Professor at Universidade Federal de São Carlos.
\end{abstract}

\section{Abstract}

I aim in this paper to articulate forms of support that have historically generated sociability around football. In order to achieve that, I discuss transformations in support sensibility that, faced by technological, marketing and subjective experiences of individualism have tended to exhaust some of public and collectivizing experiences responsible to the high projection of football as mediator of daily relations in Brazilian urban centers.

\section{Keywords}

football $\bullet$ sociability $\bullet$ fans $\bullet$ anthropology of sports $\bullet$ support.

\section{Contact}

Universidade Federal de São Carlos (UFSCar)

Rodovia Washington Luis, km 235, SP-310

13565-905 - São Carlos - São Paulo

E-mail:kike@usp.br 
O universo espetacular e especular do torcedor de futebol pode ser compreendido como uma espécie de prisma por onde milhões de aficcionados projetam e refratam infinitas frações de si mesmos uns sobre os outros. A partir dos incontáveis jogos vivenciados, interiorizando práticas num redemoinho vastíssimo de experiências compartilhadas, as potências do torcer talvez sejam aquelas que mais escapam às análises totalizantes e aos arranjos explicativos normativos, quer dos especialistas do metiée esportivo que, muitas vezes, sentenciam o comportamento torcedor a partir de um simplismo argumentativo próprio do meio, quer dos especialistas que enfrentam o assunto - historiadores, sociólogos, psicólogos, antropólogos - que acabam muitas vezes objetivando e capturando em cômodos modelos o frescor fugidio de tais experiências.

Encerradas nas performances corporais, fruto dos estímulos e situações experimentadas ad hoc, as disposições para o torcer freiam a linearidade argumentativa. Porque torcer é antes de tudo vivenciar uma interação que parece menos dependente das determinações últimas que divisam classificações seguras e preestabelecidas.

Atualmente, na maior praça esportiva do país, a cidade de São Paulo, onde se concentra o capital especulativo e circulante e de onde se propagam os discursos novidadeiros em torno do futebol profissional, se veem ou se ouvem pouco as bandeiras e os instrumentos percussivos que tradicionalmente animavam os estádios, suprimidos em nome de uma normatividade malograda nos seus propósitos políticos e jurídicos. Tal processo pode ser bastante resumido em poucos parágrafos.

Assistência foi um termo muito comum propagado pela imprensa esportiva até os anos trinta, definindo a condição dos torcedores mais populares, que se diferenciavam dos sócios, indivíduos notabilizados por laços mais estreitos, inclusive de parentesco, com os integrantes dos clubes, que se projetavam através dos primeiros campeonatos organizados e patrocinados pelos setores mais elitistas.

A inauguração do estádio do Pacaembu e a transformação do futebol em evento de massa nos anos quarenta redimensionaram o futebol na cidade de São Paulo e os espetáculos futebolísticos gradativamente tornaram-se motivo de preocupações mais detidas de parte dos poderes públicos, da imprensa e daqueles que os organizavam. Ali, numa praça esportiva que reunia pela primeira vez no Brasil um contingente expressivo de torcedores (aproximadamente 60 mil indivíduos), verificaram-se os maiores cuidados com a intolerância e as brigas entre torcedores que, diga-se de passagem, já pipocavam desde a época do amadorismo anterior aos anos trinta.

As notícias esportivas não cansavam de censurar os frequentes distúrbios e badernas promovidos por torcedores. Foi nesse momento, então, que surgiram as 
primeiras organizações de torcedores uniformizados, indivíduos que acompanhavam as partidas em bloco, cantando, exibindo faixas e cartazes homenageando jogadores, cronistas esportivos e o próprio poder público.

Reciprocamente, a imprensa esportiva e os dirigentes dos clubes prestigiavam esses grupos de torcedores justamente por acreditarem que eles formavam um núcleo civilizado no meio da massa, com atribuições específicas para além do incentivo aos times, quais sejam o de coibir e fiscalizar outros torcedores, inibindo o mau comportamento generalizado. De fato, esses grupos uniformizados respondiam aos interesses daqueles que dirigiam os espetáculos, os "cartolas" e à imprensa esportiva, e cumpriam, na visão de muitos, uma função normativa.

Sabe-se que esta situação foi alterada com o aparecimento das torcidas organizadas (TOs) já no final dos anos sessenta. Agrupamentos com nítida inspiração popular, diferentes, portanto, dos grupos uniformizados mais comprometidos com os interesses dos dirigentes esportivos, e em parte autônomos em relação aos clubes, muitas vezes em confronto explícito com os dirigentes, essas formas de torcer rapidamente se popularizaram e hoje dominam boa parte do cenário das organizações torcedoras, sobretudo na cidade de São Paulo, já que em outros estados o comprometimento com dirigentes é ainda verificado como um modelo predominante de participação dentro do futebol.

É relevante correlacionar o surgimento dessas instituições torcedoras a um contexto mais amplo de valorização das instituições populares, num período em que os direitos políticos e a cidadania estavam cerceados pelo regime militar. Contrários ao modelo autoritário que também gerenciava os times de futebol, grupos de torcedores mobilizaram-se em torno de instituições mais alternativas e paralelas ao futebol das elites dirigentes.

Desde 1995, está proibido, nos limites da urbe, o uso espontâneo ou organizado de adereços torcedores. ${ }^{1}$ Embora no decorrer dos anos tenha havido um

Tais proibições se deveram a uma série de incidentes graves e ciclos de violência envolvendo torcedores e torcidas organizadas que culminaram no episódio ocorrido em 20 de agosto no Pacaembu, na final do campeonato de juniores entre São Paulo FC e SE Palmeiras. Paus, barretes de ferro retorcidos e pedaços de concreto foram mutuamente desferidos pelos torcedores. As imagens de um jovem combalido, à deriva sobre suas próprias pernas, tropeçando pelas laterais do gramado, por fim projetado, já desmaiado, nos alambrados, demonstrava, ao vivo pela TV, o tamanho da agressividade coletiva que se instaurava naquele momento. $\mathrm{O}$ saldo foi ainda pior com a ocorrência da morte desse adolescente por lesões generalizadas. Este confronto, diverso de dezenas de outros que o antecederam, inclusive com a ocorrência de vítimas, mas que não tiveram o mesmo impacto na mídia e desdobramentos judiciais posteriores que este, se deu no gramado, fato que lhe conferia uma maior dramaticidade devido à subversão das características básicas das competições esportivas modernas, fazendo do próprio campo de jogo um espaço onde se ausentaram as regras da disputa, substituídas pelo confronto aberto entre os torcedores. 
relaxamento às proibições e algumas concessões tenham sido feitas, como é o caso da presença de alguns movimentos torcedores patrocinados pelos próprios clubes em torno dos chamados sócio-torcedores, figuração canhestra do capital em que o torcedor aparece como uma espécie de acionista minoritário do seu time-empresa, o espetáculo visual vindo das arquibancadas desde então, e até o momento, foi bastante minimizado do ponto de vista da plasticidade e corporalidade que sempre se quis emprestar às emoções de um jogo, acentuando uma postura mais individualizante e "mental" ao ato de torcer. Seria como se torcer estivesse menos compromissado com os movimentos compulsivos do remexer e do se contorcer para se prestar às elaborações mentais e supostamente intelectualistas (baseadas nas estatísticas nutridas pelos programas esportivos) no fruir do jogo, espécie de civilidade que se quer hegemonizar para o comportamento vindo das arquibancadas.

Coletivizar cada vez mais os esquemas táticos, amortizando certas individualidades corporificadas em técnicas agora tidas por extravagantes e antiéticas dentro de campo, como um drible desconcertante lançado muitas vezes pelas necessidades do próprio corpo em manter o equilíbrio instável na solução de uma jogada, parece ditar a razão última do discurso esportivo-normativo do profissionalismo em voga, que está na razão direta da necessidade elitista de individualizar também a performance daqueles que torcem, tentando, nem sempre com sucesso, alterar a dinâmica do ato paroxista do torcer, deslocando o epicentro das sensações imanentes vividas pelo e no corpo para as objetivações da mente.

Aqui, paradoxalmente, são as supostas certezas de um saber alimentado por mensurações, medições, cronometragens, cronologias, análises táticas que parecem se situar no reino de uma dada alienação em relação ao jogo, já que o torcer diz respeito ao domínio da sensibilidade mais próxima à prática, às técnicas corporais inerentes ao jogo, à explosão dos músculos, às experiências consubstanciais - o suor de jogadores e lágrimas dos torcedores (ou vice-versa) alojadas nos corpos, nutrindo e produzindo a impactante vontade de torcer. ${ }^{2}$

Movimento que parece seguir pari passu outros estímulos correlatos, como é o caso da comercialização da transmissão de jogos que repercute na necessidade imposta por uma nova conduta torcedora, a do torcedor de poltrona, que paga para ver seu time pelo sistema pay-per-view, serviço oferecido pelos canais televisivos esportivos autodenominados fechados (elitistas, pois não?). Ou ainda a

2 Para uma análise da categoria vontade, consultar o inquietante trabalho histórico-etnográfico de Buarque de Holanda (2010), citado. 
instalação de cadeiras numeradas nos estádios e o fim dos espaços populares chamados "gerais", fixando corpos a lugares, inibindo o contato físico e embotando a plasticidade em gestos seguros e contidos, domínio da privação e do privado.

O deslocamento da vontade torcedora - vontade tomada como disposição e comprometimento arrebatador - do corpo para o intelecto tem sinalizado para as transformações mais recentes ocorridas no futebol espetáculo e nas formas de torcer.

Faz parte do imaginário literário sobre futebol que o escritor Nelson Rodrigues via mal os jogos que tematizavam suas crônicas esportivas, porque, dizem, não enxergava direito das cadeiras do Maracanã. Mais preocupado com a poética do espetáculo do que com os meandros da partida assistida in loco, inventava situações, descrevia o impossível, enunciava o inimaginado. E ironizava sistematicamente aqueles que o censuravam chamando-os de idiotas da objetividade.

Pensar a corporalidade do torcer ou, de outro modo, pensar o jogo pela leitura gestual e teatral que cada torcedor faz numa ou sobre uma partida é se colocar no âmago daquilo que define a beleza plástica do futebol, o conjunto quase ilimitado de suas técnicas corporais que produzem o enredo do jogo. As imagens conhecidas de Nelson Rodrigues se contorcendo nas cadeiras do estádio e bradando em gestos a leitura que fazia dos jogos são emblemáticas dessa riqueza da gestualidade posta à prova na experiência torcedora. É fato que ele tenha escrito menos sobre a gestualidade e mais sobre a fala torcedora e são conhecidas as crônicas em que evidencia a importância do palavrão e do recurso às piadas como linguagem presente nos estádios. Mas é preciso enfatizar que a corporalidade também consiste num acesso importante, na leitura e na compreensão do jogo do ponto de vista torcedor.

Não se trata somente de maneirismos reativos ao espetáculo, mas uma postura que leva à emoção. A inteligibilidade do jogo, que diz respeito à relação entre os que jogam e os que assistem, passa necessariamente por essa adesão corpórea existente "fora das quatro linhas". Torcedores não jogam, é sabido, mas se contorcem, leem uma partida com os gestos, chutam juntos com os jogadores, como se diz comumente. A luxuriante gestualidade observada nos estádios, inibida aqui e acolá em nome de propaladas necessidades operacionais calculistas, não tem somente por função edulcorar o espetáculo, mas, antes, o constituir na sua totalidade, pois a imensa popularidade do futebol também é fruto do aprendizado corporal vindo das assistências. Formas de jogar são cúmplices das formas de torcer e para a verificação desse fato basta observar o comportamento torcedor e as escolas de futebol mundo afora. 
Mas experiências estéticas e políticas nascidas das arquibancadas jamais deixaram de existir por falta de território e os estádios há muito não abrigam o único locus da experimentação de uma vontade que certamente nasceu antes da existência deles e continuará a existir por aí nos meandros da dinâmica urbana. O domínio do cotidiano também está repleto da vontade de torcer e captar parte da sua dinâmica é a tarefa a que me proponho na sequência desse texto.

$* * *$

A pergunta que se coloca a essa altura é se pode ainda o futebol amparar redes de socialidade fulgurantes no contexto das metrópoles do ponto de vista da produção de identidades e emoções torcedoras.

Tentando desviar das armadilhas sedutoras a que a equaçãofutebol-identidade se presta nessas horas, espécie de muleta argumentativa para escorar análises amiúde, voltar a escrutinar um tema tão onipresente como a identidade, associada a não menos reificada expressão "futebol brasileiro", seria retomar alguns fios soltos que antecedem a estabilização dessa equação, ou melhor, voltar a ela mais uma vez para atentar para os pontos mais fugidios da sua solução e ver em que lugar da costura a trama esgarçaria a relação causal que se estabelece entre uma e outra.

Por isso, não é do futebol profissional que trato aqui, mas da sua recepção a partir do homem comum imerso no drapeado do cotidiano. Futebol tomado, portanto, como uma das dimensões das tantas experiências e aventuras urbanas que se sobrepõem e que enredam frações da vida de cada um de nós. Não falarei diretamente do futebol heróico, quer dizer, dos seus ritos, dramas, efemérides, personagens, enfim, das formas espetacularizadas ${ }^{3}$ assumidas ao longo do século XX como expressão dos discursos identitários emanados ou capturados pelos projetos de poder, mas do poder de sociação e socialidade que instaura, uma vez que se tornou uma linguagem verbal e, sobretudo, corporal sabidamente experimentada no seu extenso matiz.

Primeiramente, há que se problematizarem todos esses termos em discussão e gostaria de iniciar com a identidade. O senso comum apreende a noção de identidade a partir da preeminência da percepção individual, produzindo uma extensão do "eu" na contiguidade dos interesses, no manuseio dos sistemas simbólicos, nas escolhas, racionais ou afetivas, que se crê fazer o tempo todo. Nesse caso, o processo de identificação partiria de vontades pessoais, e a sujei-

3 Para uma análise detida do futebol espetáculo, consultar Damo, citado. 
ção ao universo social dependeria, em grande parte, de trajetórias supostamente singulares e biográficas.

Outros, entre os quais me incluo, problematizam tal noção realocando os termos. Identidade aí seria concebida como experiência compartilhada, algo que surge da relação do nosso eu com outras subjetividades, e seria da tensão entre subjetividades que nasceria alguma forma de relação identitária. Portanto, ela não estaria livre e submetida permanentemente às escolhas individuais, ao nosso mero fluxo de desejos e interesses imediatos, expressão de um amor de si mesmo, mas sim disposta numa dimensão sempre reposicionada pela dinâmica das relações que nos enredam e nos projetam para fora de nós mesmos, problematizando e mesmo borrando, chave de toda essa questão, os limites da percepção que experenciamos do próprio eu.

Torcer é fustigar a esfera segura da individualidade e, nessa medida, seria como que experimentar extensões, torções e projeções do "eu" na esfera pública, ou, aproximando-nos de conceituações como as de Gell, tornar-se torcedor seria como que "distribuir a pessoa" num universo integrado por outros milhares de indivíduos, coisas, objetos, seres cosmológicos, todos arrebatados e articulados pela arte e artefato do futebol: camisetas dos times queridos, bolas, troféus, chaveiros e essa infinidade de souvenires avidamente disponibilizados pela e para a vontade torcedora expressam algo muito maior do que a mera compulsão consumista, pois há algo de nós nesses objetos, há algo dos objetos agenciados em nós.

Mais do que a suposta certeza do que sempre somos (meu nome e meu RG assegurariam isso no plano existencial e jurídico-formal), caberia a dúvida classificatória sobre quando e em que circunstâncias, afinal, somos algo. A vivência urbana multiplica a experiência das identidades em estímulos potencializados pela forma tecno-social que é o contexto metropolitano, como bem mostraram, há tempos, autores como Simmel.

Portanto, não estaríamos tão-somente sob a égide do verbo ser, mas também do verbo ter que igualmente, ou mais, produziria as mediações entre nossas vontades e experiências como indivíduo e as demandas coletivas, e entre nossas experiências coletivas em relação às outras tantas com as quais travamos conhecimento e troca, as ditas "outras culturas". Introduzimos nesse mar de essencialismos a-históricos do tipo "somos brasileiros", "somos torcedores deste ou daquele time", somos isso ou aquilo, uma pitada de dúvida produtiva. Afinal, somos até quando e com que intensidade, desapossados o tempo todo de certos valores que julgávamos tão caros?

As expressões um tanto banais "Brasil, país do futebol" ou "sou torcedor do time X" trazem consigo níveis de acomodação existenciais e políticas que 
demandam por atualizações e novas posses. Formas institucionais de atualizar a expressão "Brasil, país do futebol" estariam mais ou menos garantidas tanto do ponto de vista da memória reificada dos tempos heróicos - a mídia memorialista é responsável por sua manutenção - quanto pelo vigor do próprio futebol de Estado, encabeçado pelo universo profissional, que reaviva expressões como esta a cada quatro anos nos megaeventos denominados copas do mundo.

Na expressão genérica "sou torcedor do time X" parece que estão em jogo formas múltiplas e negociadas de apropriação simbólica se tomadas do ponto de vista solitário das vontades que habitam cada torcedor. Torcer não é como portar o RG, garantia de estabilidade do eu ante as razões de Estado, pois torcer faz parte de um universo de experimentações mais sujeitas às instabilidades de toda ordem. Está ou é o próprio fluxo da vida. Somos mais fanáticos numa determinada época das nossas vidas, amortecemos a paixão em alguns momentos para voltarmos a nos apaixonar em outros, inventamos novas rivalidades, reavivamos e reivindicamos a emoção torcedora na chegada de um filho, escutamos, de torcedores nos estádios, geralmente após derrotas humilhantes ante arqui-inimigos, que não voltarão mais a torcer, para tudo recomeçar novamente num outro instante, enfim, infinitas situações põem à prova a vontade torcedora, contorcendo a identidade (clubística, nacional) a todo instante.

Por isso, as formas mais hierarquizadas e "administrativas" de torcer, sobretudo abrigadas nas torcidas organizadas, não reproduzem toda a extensão e a riqueza fenomenológica do ser torcedor. Ambientadas e nutridas nas dinâmicas de poder, as TOs reproduzem todos os sucessos e fracassos das formas institucionalizadas que conformam aquilo que se define como "sociedade", e nenhum dos aspectos escapam a elas: burocracia, hierarquias estabelecidas (mando e obediência), lógicas de distinção, comprometimentos políticos com projetos coletivos próprios ou negociados com outros atores, parlamentarização das relações e violência instrumental. ${ }^{4}$

De todo modo, a intromissão de um verbo como o ter, portanto, traria alguma inquietação às identidades, pois somos aquilo que em grande medida conquistamos, sobretudo à revelia dos outros, e, ao tomar posse, conservamos como nosso aquilo que é patrimônio coletivo.

A experiência urbana e o futebol revelam em muito essa dinâmica processual das identidades. Basta uma volta pelas ruas e perceberemos, rapidamente, que

${ }^{4}$ Norbert Elias tratará da questão da pacificação da violência numa chave psicologizante e evolutiva. 
a paisagem torcedora mudou de duas décadas para cá, visivelmente anunciada na multiplicação do vestuário esportivo que sugere a maior ou menor adesão dos jovens aos times europeus, seus campeonatos televisionados, seus ídolos internacionais, certames que expõem atletas brasileiros re-territorializados, que assumem novas éticas e condutas mais ascéticas marcadas pelas experiências no futebol profissional globalizado, para desagrado de muitos que foram socializados (e estabilizados) pela lógica torcedora que vincula o futebol a algum tipo de identidade (local, nacional). Mudaram os jogadores, os torcedores ou o jogo das identidades na dinâmica das cidades globais? Certamente tudo isso ao mesmo tempo.

Quero com isso sintetizar dizendo que identidade não está relacionada às livres escolhas que fazemos no plano do cotidiano. Apenas para pensar numa comparação algo descabida, escolher uma casa para comprar, que envolve cálculos de gosto, de distinção social, somados aos cálculos econômicos, não estaria na mesma ordem de coisas como escolher um time de futebol para torcer, disso nós sabemos, que é quase que intuitivo e, na verdade, sequer comparamos essas coisas. Identidade tem algo a ver também com transcendência e as aproximações ou distanciamentos que fazemos em relação aos elementos disponíveis, por mais que passem pelo nosso crivo individual, ganham certa autonomia de nós mesmos. Existe uma identidade em torno da seleção que independe do grau de adesão individual deste ou daquele sujeito, pois a posse é coletiva, compartilhada. Sofremos juntos, digamos assim.

No mínimo, outras dimensões menos tangíveis entrariam no cálculo da soma dos fatores que levam à identidade torcedora. Em tese, ela estaria associada menos aos marcadores sociais de classe e ideológicos e mais às relações societárias primárias, frequentemente manifestadas no interior das famílias, das parentelas, dos círculos de amizade (bairros, escolas, clubes etc.), ao estatuto de pessoa em jogo, até no exercício contínuo das relações contrastivas de gênero, enfim, lugares privilegiados em que nascem as disposições para torcer. Tais disposições não viriam somente de algum cálculo interesseiro, instrumental ou fruto de inquietações solitárias do "eu". É o conjunto complexo de identidades experimentadas e em confronto, manifestadas num único sujeito, que ditará se o futebol pode ser ou não uma forma viável de socialidade. Identidade é também concebida como a produção de pontos de vista sobre o mundo, daí segue seu caráter relativista.

Acho que isso está mais ou menos claro. Mas a identidade traz ainda outro aspecto. Ninguém torce sozinho. E mais, ninguém torce a favor de um time sem se contorcer por outros. E essa seria a outra face da identidade, a produção das diferenças, desapossamento dos outros, nomeados de várias maneiras (oponentes e inimigos que recebem toda carga de categorias jocosas de acusação que grassam 
entre torcedores: porcos, bambis, galinhas etc.) que, num regime competitivo como os esportes, suportam relações conflitivas de toda ordem. Não é à toa que o futebol nasce nas sociedades competitivas modernas, espacializadas na forma segmentada das cidades e metrópoles.

A diferença é instaurada no mesmo movimento que a identidade, produzindo um regime de contraste entre as coisas - times de futebol, por exemplo - definindo os contornos de um sistema classificatório. Ou seja, há um sistema de oposições entre times que dinamizam e nos disponibilizam, aproximando indivíduos, afastando outros, mas todos, de algum modo, comprometidos com um sistema inclusivo e dinâmico.

Identidade e alteridade variam com os níveis de abrangência: o time da escola, o time do bairro, o time do futebol profissional, seleções nacionais; todas essas valências produzem ao mesmo tempo identidades e diferenças. Mas fica a pergunta, elas existem de fato, mensuram coisas? O que distinguiria um corintiano de um são-paulino ou um palmeirense de um santista? A resposta está no próprio sistema de diferenças, é ele que mobiliza nossas paixões e adesões para além da identidade solitária que mantemos por um único time.

Há gradações do torcer que variam da adesão incondicional ao ódio mortal por um determinado oponente, mas que também variam com as circunstâncias que guardam historicidades que não podem ser desprezadas. Basta observar que rivalidades preferenciais se alternam com o tempo, com a faixa etária, com o aumento dos confrontos entre rivais. Sabe-se, por exemplo, que uma partida entre Palmeiras e Corinthians mobilizava quase que exclusivamente o jogo de rivalidades na cidade décadas atrás, mas entre os jovens palmeirenses da atualidade, o confronto com são-paulinos ganha expressiva relevância nesse sistema de rivalidades. Enfim, temos que jogar contra alguém, desapossar o oponente (da bola, da possibilidade do ganho, da piada e da jocosidade disparadas no dia seguinte na escola, no boteco etc.).

Apesar de tudo isso, ainda é comum ouvir que o futebol ocupa espaços periféricos no mundo social ou que seria algo de menor importância ou ainda que consistiria num fenômeno que produz somente identidades efêmeras do ponto de vista das decisões (individuais ou coletivas) que fazemos em nossas vidas. Outras identidades seriam consideradas mais sérias e decisivas, como o sentimento de pátria, vinculado às variadas formas de conivência política que pactuamos, ou identidades étnicas, que igualmente definem parâmetros existenciais para muitos de nós.

Mas se o futebol não possui tal centralidade e, portanto, não o vivenciamos como uma experiência totalizadora em nossas vidas, supondo sermos todos 
torcedores comuns e não militantes das TOs, o convívio dentro do seu regime classificatório contrastivo proporciona o exercício maior da relativização no convívio com a diferença, condição política necessária para se experimentar qualquer dinâmica no contexto urbano, marcado pelas diferenças sociais, ideológicas e étnicas. Aprendemos algo com ele em relação aos aspectos que definem nossas outras identidades, pois se trata de mais um arranjo simbólico de adesão do indivíduo ao social no jogo das identidades a que estamos continuamente submetidos.

Tomemos agora o contexto urbano como o lugar de nossas experiências identitárias mais imediatas, pois é aí que somos, de fato, mais ou menos brasileiros, mais ou menos japoneses, migrantes, são-paulinos, santistas, flamenguistas ou quaisquer outras condições que nos agregam e diferenciam dentro desse feixe de sistemas classificatórios justapostos que nos moldam.

Mas não conseguimos falar do urbano hoje sem resvalar no problema da violência. Não seria o caso de inventariar as formas da violência urbana. Trabalhos de todos os matizes ideológicos estão aí para serem consultados. Quero somente articular a condição de torcedor de futebol ao urbano e reposicionar sua relativa importância na esfera da socialidade. Sabemos também da violência simbólica a qual o futebol moderno está submetido: contratos milionários, superfaturamento, especulações, lavagem de dinheiro, interesses econômicos de toda monta, desgaste da paixão e do interesse dos jogadores pela seleção brasileira, espetacularização desenfreada do jogo, truculência entre torcedores.

Mas outro tratamento ao tema deve ser observado e que teria a ver com aquilo que chamo de virtualização de uma socialidade. Quer dizer, serei malandro, estudante, jogador, torcedor, trabalharei com meu pai, todos esses aparentes dilemas banais que povoam o início da vida adulta (momento de intensa captura e mobilização das paixões) que fazem parte da biografia de cada um e que dizem respeito aos questionamentos da ordem da subjetividade mobilizam grande parte da dinâmica das classes populares urbanas e não devem ser vistos como momentos estanques. Tirem o futebol e coloquem o tráfico, tirem o tráfico e coloquem os estilos de vida (rappers, por exemplo, ou o universo do samba, ou ainda a esfera da religiosidade etc.), recoloquem o futebol, enfim, o que quer que apareça como ênfase vai denunciar um espelhamento entre essas coisas todas.

O que quero ressaltar, dito de outra maneira, é a forma de apreensão do futebol como marcador dessas identidades descontínuas que experimentamos a todo o momento no contexto urbano, bem observada por inúmeros estudiosos 
da sua dinâmica. ${ }^{5}$ Dependendo do interesse, da adesão aos estilos de vida, da condição de classe, da territorialização de um peculiar modo de vida, motivações diversas, portanto, acionamos distintos e até mesmo antagônicos papéis sociais. Coexiste num mesmo indivíduo a condição de trabalhador, malandro, bandido, pai, filho, torcedor, policial e tantas outras ocupações e práticas disponíveis que atravessam e dão os contornos fluidos às nossas biografias.

Por ser uma esfera periférica, afastado imediatamente das decisões mais prementes que comandam todas essas existências ditadas por essa plasticidade da condição urbana, é que o futebol pode iluminar certas condutas, práticas sociais e manejos simbólicos que nos libertam da barbárie e da violência a qual estamos imersos na vida cotidiana da cidade. Pois ele possui a qualidade de ser uma espécie de marcador zero da socialidade. É por seu intermédio que infinitas conversas começam e terminam, mobilizando a vida cotidiana de milhares de pessoas, e ainda de quebra ensinando algo com sua dinâmica no jogo contrastivo oferecido pelo urbano. Comprimo essas formas de adesão mais ou menos desinteressadas e mantidas por nós em relação ao futebol numa expressão, socialidade lúdica. Socialidade lúdica seria um sistema inclusivo de discursos ou fragmentos de discursos que definem práticas que independem das condições objetivas que nos aparta na vida da cidade - as determinações de classe, as categorias profissionais, os estilos de vida, as escolhas ideológicas.

A socialidade lúdica, tomando o futebol do ponto de vista dos torcedores comuns, repito, exprime baixa densidade instrumental, mas organiza o discurso do senso comum, no sentido de estabelecer uma interação que deve ser, obrigatoriamente, tomada como "não séria". É aí que reside o caráter dialético dessa relação social: a "obrigação" de uma "não seriedade" como emuladora de um "desinteresse" que permeia a dimensão da socialidade urbana. Estamos no domínio de alguns dos elementos que definem a reciprocidade como condição de possibilidade da vida social, no plano dos divertimentos. ${ }^{6}$ É possível que a dimensão da reciprocidade apareça com mais visibilidade nesse domínio da paixão desinteressada dos torcedores, pois consiste num aspecto difícil de ser capturado pela lógica do mercado e pela lógica da política, embora também o seja em alguma medida, mas que, em todo o caso, segue um fluxo próprio, meio que à deriva, denunciando uma modalidade de socialidade expressiva.

\footnotetext{
5 Apenas para citar alguns trabalhos, ver Spaggiari (2009) para pensar na relação entre futebol, socialidade e o contexto urbano, ou Feltran (2008) para compreender a dinâmica das periferias de São Paulo do ponto de vista da lógica fronteiriça entre o legal e o ilegal.

6 Para verificar o conceito de reciprocidade, consultar o clássico trabalho de Mauss (1974).
} 
Começar qualquer conversa acionando o futebol e seus temas - a lembrança de um ídolo esportivo, uma polêmica partida realizada no dia anterior, uma discussão de quem seria melhor ou pior - é posicionar a relação social numa espécie de grau zero de reciprocidade, pois aparentemente nada se pode esperar dela a não ser que esteja inscrita na lógica da própria interação, a de discutir seriamente sobre o não sério. Por muito tempo, a máxima Futebol política e religião não se discutem foi utilizada no senso comum para aplacar qualquer esquiva ou contenda, reprimindo o diálogo e sentenciando que tais adesões seriam ou imutáveis ou inatingíveis do ponto de vista da crítica e do diálogo, sobretudo num momento em que a vida política do país estava sob suspeição. Parece que tal máxima caiu num certo desuso ou ostracismo no mundo globalizado que disponibiliza tantas formas de democracia, religiosidade e times para torcer.

Nada, no ambiente urbano, parece soar mais banal, mas por isso mesmo mais seguro do ponto de vista da desconfiança generalizada que se produz na cidade - sobretudo num contexto em que a esquiva, a manipulação de papéis sociais e a violência urbana aproximam e distanciam indivíduos - do que uma conversa "jogada fora" sobre qualquer assunto em torno do futebol. É possível que essa experiência fugaz, da ordem da dinâmica cotidiana, reserve alguma lição para compreendermos o tipo de subjetividade e adesão às identidades que experimentamos no meio urbano.

As operações intelectuais dicotômicas, que amparam muitas das análises e os usos políticos que norteiam a vida na metrópole, impondo um perverso e intolerante "nós versus eles", um "público versus privado", um "centro versus periferia", um "poder público versus cidadãos", uma ordem legal versus a ilegal, deveriam ser questionadas a partir de estruturas simbólicas de maior inteligibilidade. E o universo lúdico, vindo da experiência torcedora corporificada e experimentada pelo homem comum, parece consistir numa via para se repensar a diversidade existente na metrópole, uma vez que somos, para utilizar uma expressão grave do antropólogo Lévi-Strauss, "inelutavelmente homens".

Apropriar-se da dimensão lúdica, por mais insignificante que possa parecer, instrumentalizando-a como política pública, tem sido um dos maiores desafios dos sucessivos manejos políticos. Parece que reside aí uma das esperanças contra a barbárie moderna. Mas implementar tais políticas resvala quase sempre nas dificuldades em reificar a dimensão lúdica, pois as maneiras criativas de vivenciála nunca são detidas ou tomadas por nenhum partido, programa de governo ou discurso intelectualizado. Desapossada e desterritorializada, a socialidade torcedora, espécie de metafísica do homem comum, forma um patrimônio de todos num jogo livre e dinâmico imposto pela lógica das identidades sempre fugidias. 


\section{Referências bibliográficas}

BUARQUE DE HOLANDA, Bernardo. O clube como vontade e representação: o jornalismo esportivo e a formação das torcidas organizadas do Rio de Janeiro. Rio de Janeiro: 7 Letras/Faperj, 2010.

COSTA, Carlos Eduardo \& TOLEDO, Luiz Henrique (orgs.). Visão de jogo: antropologia das práticas esportivas. São Paulo: Terceiro Nome/Fapesp, 2009.

DAMO, Arlei. Futebol e identidade social. Uma leitura antropológica das rivalidades entre torcedores e clubes. Porto Alegre: Editora da Universidade (UFRGS), 2002.

DAMO, Arlei. Do dom à profissão: a formação de futebolistas no Brasil e na França. São Paulo: Hucitec, Anpocs, 2007.

ELIAS, Norbert. Em busca da excitação. Lisboa: Difel, 1992.

FELTRAN, Gabriel. Fronteiras em tensão. Um estudo sobre política e violência nas periferias de São Paulo. Tese de Doutorado, Campinas, IFCH-Unicamp, 2008.

GELL,Alfred. Artand agency: an anthropological theory. Oxford: Clarendon Press, 1998. HUIZINGA, J. Homo ludens. São Paulo: Perspectiva, 1993 [1938].

LÉVI-STRAUSS, C. Introdução à obra de Marcel Mauss. In: MAUSS, M. Sociologia e Antropologia. São Paulo: Edusp, 1974.

MAUSS, Marcel. Sociologia e Antropologia. São Paulo: Edusp, 1974.

RODRIGUES, Nelson. À sombra das chuteiras imortais. São Paulo: Cia. das Letras, 1992.

SIMMEL, George. A metrópole e a vida mental. In: VELHO, Otávio (org.). O fenômeno urbano. Rio de Janeiro: Jorge Zahar, 1972.

SPAGGIARI, Enrico. Tem que ter categoria. Construção do saber futebolístico. Dissertação de Mestrado, São Paulo, PPGAS-USP, 2009.

TOLEDO, Luiz Henrique. Torcidas organizadas de futebol. Campinas: Autores Associados/Fapesp, 1996.

TOLEDO, Luiz Henrique. Lógicas no futebol. São Paulo; Hucitec/ Fapesp, 2002.

TOLEDO, Luiz Henrique. Prefácio. In: BUARQUE DE HOLANDA, Bernardo. $O$ clube como vontade e representação: o jornalismo esportivo e a formação das torcidas organizadas do Rio de Janeiro. Rio de Janeiro: 7 Letras/Faperj, 2010.

TOLEDO, Luiz Henrique. Brazilian soccer: symbolic dimensions of its practice. In: CURI, Martin (org.). Football in Brazil. London: Routledge, 2010.

VELHO, Gilberto. Individualismo e cultura. Notas para uma antropologia da sociedade contemporânea. Rio de Janeiro: Jorge Zahar, 1981.

Recebido: 09/11/2009 - Aprovado: 24/05/2010. 